Carolo Mayer, Augustissimi Im-smothered mate. Similar situperatoris, et totius Rossiæ auto-ations occur very frequently in cratoris Medico aulico, \&c. Pars play, and the amateur will judge prima. Petropoli, 1823. for hirnself whether it is proba-

A Society has been lately ble that the. series of moves by formed at Geneva, called $L a$ So- which the mate is effected, was cieté de Traduction, for the pur- irst discovered at the commencepose of translating into French in the later editions of Hoyle's all foreign Surgical works of games, this problem is called merit. 'The society already 'Philidor's legacy;' hence among ranks among its Members, M.M. the ordinary class of players, PhiMaunoir, Mayor, Morin, Dussin, lidor has obtained the credit of Olivet and Peschier. This last bequeathing to posterity a posiGentleman is corresponding se- tion which was published three cretary, and all works for trans- centuries ago. Of Mr. Hoyle's lation must be transmitted to pretensions to give instructions in Paschoud at Paris, through Bos- the game of Chess, the following sange and Co. London, addressed to M. Peschier.

passage, which we cite from one of the editions, authenticated by the autngraph of the author $(1750)$, affords a pleasant specimen.

Shetches of Medical speakers. No 2.-Dr. Harrison, and an article on a recent Correspondence between Dr. Clark, of Edinburgh, and Professor Tommasini, of Rome, on the comparative advantages of the English and Italian systems of Medical education, will be given in our next.

- Supposing your queen and another piece are attacked at the same time, and that by removing your queen you must lose your piece; in this case, if you can get two pieces in exchange for your queen, I would advise you rather to do it, than retire; for observe, 'tis the difference of three pieces, which is more than the worth of a queen; besides

The Title-page and Index to that you keep your game entire, the first Volume of THE LANCET, and preserve your situation, which will be ready for delivery in a very often is better than a piece; few days. nay, rather than retire, I would give my queen for a piece and a pawn or 1 wo ; nay, ulmost for CHESS PROBLEMS. No. 7. what I cun get !'

The next problem affords a beautiful illustration of the smoWe observed in our last num- thered mate, differing materially ber, that the smothered mate given from the partito of Damiano, and by the Knight is said to have most of the positions which have been discovered by Damiano. - been founded upon it. It may be The first of the following prob- necessary to apprize the student, lems is the position, as it is given that the mate is required to be in Damiano's treatise, illustrating given in six moves, on the supm the scacco-matto affogato, or position of the black protracting 
it by the sacrifice of his queen for Knight at adverse queen's fourth nothing; without this sacrificesquare.

the mate would be given in five Pawn at the king's rook's semoves.

The last is an original problem. The arrangement of the position is similar to that in Professor Wildt's problem, but the mate is required to be effected with fewer pieces, and in a less number of moves.

In compliance with the request $\mid$ and quares. of several Correspondents, we annex the solution of Problem 11 . cond square.

King at his queen's knight's square.

Rook at queen's square.

Rook at king's rook's square.

Pawns at queen's rook's second and queen's knight's second $\mathbf{X X}$.

The black having played his Cady will see the necessity of queen's bishop to his king's third pausing before he finally decides.

We like rational incredulity, most. and we are aware that our Legal Correspondent is taught by the law, which is ' the perfection of reason,' to believe nothing in the absence of evidence. He will perceive, however, that we observe a maxim of his own profession, Neminem cogimus ad impossi. bilia.

We are flattered by Danican's polite communication ; but we repeat that The Lancet is invisible.

We will answer X. Y. by telling him a story. When Foote set up his carriage for the second time, he took for his motto the word." iterum." He lost his fortune, recovered it, and launched his carriage a third time. $\mathrm{He}$ then chose for his motto "iterumque."

\section{Problen XIX.}

The white is required to give check-mate to his adversary in five moves.

Position of the Pieces. WHITE.

King at his rook's square. Queen at adverse king's bishop's suare. third square.

\section{Position of the Pieces.}

\section{WHITE.}

King at his rook's square.

Queen at her bishop's four th quare.

Rook at queen's rook's square. King's bishop at adverse king's rook's fourth square.

Queen's bishop at its square.

King's kn:ght at king's hishop's third square.

Queen's knight at adverse queen's fourth square.

Pawns at king's rook's third, king's rook's second, king's fourth, adverse king's fourth, queen's bishop's second, queen's knight's second, and queen's rook's second squares.

King at his knight's square.

Queen at her square.

King's rook and queen's rook at their squares.

King's bishop at king's second square.

Queen's bishop at its square.

Knight at queen's bishop's third king's knight's second, king's bi 
shop's third, queen's bishop's second, queen's bishop's fourth, queen's knight's second, and queen's rook's second squares.

\section{XXI.}

TABLE TALK.

Liberty of the Press.-The Royal Medical Society of Edin. burgh, anxious either to protect their own rights, or to prevent

White to give checkmate with any abuse of the liberty of the the pawn in six moves, without press, have actually presented a taking any of the adversary's Bill of Suspension and Interdict pawns, and without losing either - or in other words, applied for of his own pieces.

Position of the Pieces.

WHITE.

an injunction - to prevent Messrs. Oliver and Boyd, the printers, and Dr. Poole, the Editor of The Edinburgh Phrenological Journal, from publishing any report

King at adverse queen's third of the Delate on Phrenology square.

which recently took place in Dr.

Queen at the king's rook's third Duncan's class-room in the Unisquare.

Rook at the queen's rook's third square.

Bishop at the queen's bishop's third square.

Pawn at the queen's knight's second square.

\section{BLACK.}

King at the queen's rook's secoild square.

versity, and to which strangers, if not invited, were admitted. -Scotsman.

Musical Phenomenon.--Paris at this moment possesses a real phenumenon, in a young Hungarian, aged eleven years, named Leist. This child already displays talents of the first order as a pianist; but the execuition of young Leist is not only distinguished for rapidity of fingering,

Pawns at the queen's rook's which is what is admired in a third square, queen's rook's fourth number of performers; he unites square, and adverse queen's rook's to a perfection of lightness and fourth square, and at the queen's firmness of hand, an expression bishop's third square, queen's bi- which has been wanting in other shop's fourth square; and adverse performers, whose reputation is, queen's bishop's fourth square.

\section{Solution of Problem II.}

nevertheless, very high. This, however, is what is least astonishing in the talents of this extraordinary child. He composes in 1. Rook to adverse king's the style of the greatest master;, fourth square.

2. Rook to adverse king's square, checking.

3. Knight to adverse queen's third square, checking.

4. Pawn one square, giving checkmate. and he improves on lessons given him with a facility so much the more marvellous as the force and grace of idęas never fail him. Since Mozart, who astonished several Courts of Europe at the age of eight years, the musical world has certainly witnessed 